\title{
Níveis de Proteína Bruta em Suplementos Múltiplos para Terminação de Novilhos Mestiços em Pastejo Durante a Época Seca: Desempenho Produtivo e Características de Carcaça
}

\section{Edenio Detmann1, Mário Fonseca Paulino ${ }^{2}$, Joanis Tilemahos Zervoudakis ${ }^{3}$, Paulo Roberto Cecon $^{4}$, Sebastião de Campos Valadares Filho ${ }^{5}$, Lúcio Carlos Gonçalves ${ }^{6}$, Luciano da Silva Cabral $^{9}$, André José Nunes Melo ${ }^{8}$}

\begin{abstract}
RESUMO - Objetivou-se avaliar o desempenho produtivo e econômico de novilhos mestiços, suplementados, durante o período seco do ano. Foram utilizados 25 novilhos mestiços holandês x zebu, com idade e peso médios iniciais de $367,7 \mathrm{~kg}$ e 24 meses, manejados em cinco piquetes de Brachiaria decumbens (3 ha). Foram fornecidos suplementos, na quantidade de $4 \mathrm{~kg} / \mathrm{animal} /$ dia, constituídos por fubá de milho, grão de soja integral, uréia, sulfato de amônia e mistura mineral, sendo formulados para apresentarem níveis de 12, 16, 20 e 24\% de proteína bruta (PB), com base na matéria natural, os quais constituíram os tratamentos S12, S16, S20 e S24, respectivamente. Paralelamente, instalou-se tratamento controle (SAL) no qual os animais receberam exclusivamente mistura mineral. A variação dos níveis de PB dos suplementos conferiu comportamento quadrático sobre as variáveis ganho médio diário (GMD), peso vivo final (PVF) e dias necessários para o alcance de $450 \mathrm{~kg}$ de peso vivo (D450), as quais apresentaram respostas críticas sobre os níveis de 19,53\% (0,943 kg), 19,38\% (465,8 kg) e 19,22\% (90,6 dias) de PB, respectivamente. O fornecimento de suplementos permitiu desempenho superior em comparação aos animais não suplementados, os quais apresentaram médias de 0,277 kg, 397,4 kg e 312,4 dias para GMD, PFV e D450, respectivamente. O rendimento (RC) e as proporções de tecidos muscular, adiposo (TA) e ósseo (TO) da carcaça não foram influenciados pela composição de suplementos. Contudo, animais suplementados apresentaram maiores RC e TA e menor TO em comparação a SAL. A avaliação econômica de suplementos, de forma diferencial ao tratamento controle, mostrou maior renda bruta para S20.
\end{abstract}

Palavras-chave: Brachiaria decumbens, ganho de peso, rendimento de carcaça

\section{Crude Protein Levels in Multiple Supplements for Finishing Crossbred Beef Cattle at Pasture During Dry Season: Productive Performance and Carcass Characteristics}

ABSTRACT - The objective of this study was to evaluate the productive and economical performance of supplemented crossbreed steers during the dry season. Twenty five holstein x zebu steers, with $367.7 \mathrm{~kg}$ of live weight and 24 months old, grazing in five paddocks of Brachiaria decumbens ( $3 \mathrm{ha}$ ), were used. The supplements were constituted of grounded corn, whole soybean seeds, urea, ammonium sulfate and mineral salt, and were formulated to contain levels of 12, 16, 20 and $24 \%$ crude protein (CP) as fed basis, which constituted the treatments S12, S16, S20 and S24, respectively. The supplements were supplied to the animals in the level of $4 \mathrm{~kg} / \mathrm{animal} / \mathrm{day}$. A group of animals were allotted to untreated control treatment (SAL) and received exclusively mineral salt. CP levels in the supplements caused quadratic outcome on the variables average daily gain (ADG), final live weight (FLW) and necessary days to reach $450 \mathrm{~kg}$ of live weight (D450), which presented critical responses on the CP levels of $19.53 \%(0.943 \mathrm{~kg}), 19.38 \%$ $(465.8 \mathrm{~kg})$ and $19.22 \%$ (90.6 days), respectively. The supplementation allowed superior animal performance compared with SAL, which presented averages of daily gain, FLW and D450 of $0.277 \mathrm{~kg}, 397.4 \mathrm{~kg}$ and 312.4 days, respectively. The carcass dressing percentage (CD) and the proportions of muscular, fatty (FT) and bone (BT) tissues in the carcass were not influenced by the composition of supplements. However, supplemented animals presented larger CD and FT and smaller BT compared with SAL. The economical evaluation of the supplements showed larger crude income for S20.

Key Words: Brachiaria decumbens, carcass dressing, weight gain

\footnotetext{
1 Zootecnista, DS, Professor Associado, LEAG, UENF, Campos dos Goytacazes, RJ (detmann@uenf.br).

2 Eng.-Agrônomo, DS, Professor Adjunto, Departamento de Zootecnia, UFV (mpaulino@ufv.br).

3 Zootecnista, DS, Bolsista DCR - CNPq, Universidade Federal do Mato Grosso (joanis@pop.com.br).

4 Eng.-Agrônomo, DS, Professor Adjunto, Departamento de Informática, UFV (cecon@dpi.ufv.br).

3 Zootecnista, DS, Professor Titular, Departamento de Zootecnia-UFV (scvfilho@ufv.br).

6 Eng.-Agrônomo, DS, Professor Adjunto, Escola de Veterinária, UFMG.

7 Zootecnista, DS, Professor Adjunto, Universidade Federal do Mato Grosso, Cuiabá-MT.

8 Zootecnista, estudante de Mestrado, Universidade Federal de Goiás-GO.
} 


\section{Introdução}

O processo de globalização tem causado grandes mudanças em diversos setores do agronegócio. A produção de gado de corte no Brasil tem sido desafiada para o estabelecimento de sistemas de produção que sejam capazes de produzir, de forma eficiente, carne de boa qualidade a baixo preço. Além disso, estes sistemas têm de ser competitivos, sustentáveis e capazes de produzir animais para abate com menos de 42 meses de idade, que é a média nacional (Euclides et al., 2001).

A modernização da pecuária de corte brasileira, a qual possui base sólida em sistemas pastoris, envolve, de forma concreta, o conhecimento dos fatores nutricionais limitantes à produção, exigindo o emprego de suplementos de características múltiplas, permitindo ao animal melhor utilização dos recursos forrageiros, e ao sistema a ampliação do fluxo de produtos e melhor exploração de seu potencial produtivo. A forma como os suplementos múltiplos para bovinos em pastejo são formulados e administrados depende diretamente dos objetivos traçados para o sistema de produção e do potencial produtivo da área empregada. Segundo Paulino (2000), quando se almeja a produção de novilho precoce a pasto, com terminação coincidente com a época seca, envolvendo ganhos superiores a $800 \mathrm{~g} / \mathrm{dia}$, devem-se fornecer maiores quantidades de suplementos, em torno de $0,8-1,0 \%$ do peso vivo.

Em estudo recente, avaliaram-se diferentes fontes protéicas na composição de suplementos para terminação de bovinos em pastejo, encontrando-se níveis satisfatórios de ganho, superando $1 \mathrm{~kg} / \mathrm{animal} /$ dia, em pastagem de Brachiaria decumbens (Paulino et al., 2002). No entanto, estudos que envolvam características quantitativas, englobando balanceamento e otimização dos níveis de nutrientes, são praticamente inexistentes em condições tropicais, fazendo com que as recomendações atuais assumam características indesejavelmente empíricas.

Entre os nutrientes limitantes à produção animal, os compostos nitrogenados assumem natureza prioritária durante o período seco do ano, onde os baixos teores na pastagem limitam a atividade dos microrganismos ruminais, afetando a digestibilidade e o consumo de forragem, acarretando baixo desempenho animal. Segundo o Commonwealth Scientific and Industrial Research Organization - CSIRO (1990), na produção de animais em pastejo, notadamente em pastagens tropicais e subtropicais com teores reduzidos em proteína bruta, torna-se importante especificar e fornecer os requerimentos protéicos o mais precisamente possível, permitindo, desta forma, identificar, efetivamente, os procedimentos mais econômicos de suplementação e contornar entraves produtivos diversos. Embora a literatura aponte resultados positivos sobre o consumo e digestão com aumento na quantidade ou nível de compostos nitrogenados em suplementos múltiplos (DelCurto et al., 1990a, b; Hannah et al., 1991), não foram encontrados relatos na literatura nacional envolvendo variações nos níveis protéicos em suplementos múltiplos para terminação.

Dessa forma, objetivou-se avaliar o efeito de diferentes níveis de proteína bruta em suplementos múltiplos sobre o desempenho produtivo, características de carcaça e parâmetros econômicos de bovinos mestiços em fase de terminação, manejados em pastagens de Brachiaria decumbens, durante a época seca.

\section{Material e Métodos}

O experimento foi realizado nas dependências da Central de Experimentação, Pesquisa e Extensão do Triângulo Mineiro da Universidade Federal de Viçosa (CEPET/UFV), no município de Capinópolis, localizado na macro-região do Pontal do Triângulo no Estado de Minas Gerais, entre os meses de julho e outubro de 2000.

A área experimental foi constituída por cinco piquetes de três hectares cada, cobertos uniformemente com a gramínea Brachiaria decumbens Stapf., providos de bebedouro e comedouro coberto.

Avaliaram-se suplementos constituídos por fubá de milho, soja grão integral, uréia, sulfato de amônia e mistura mineral, balanceados, segundo análise prévia, para apresentarem os níveis de 12, 16, 20 e 24\% de proteína bruta (PB), com base na matéria natural, os quais constituíram os tratamentos $\mathrm{S} 12, \mathrm{~S} 16, \mathrm{~S} 20 \mathrm{e}$ $\mathrm{S} 24$, respectivamente. Fixou-se, no balanceamento dos suplementos, em 3:1 a relação entre os compostos nitrogenados oriundos de alimentos concentrados e àqueles fornecidos pela mistura uréia/sulfato de amônia (9:1). Em adição, instalou-se tratamento controle (SAL) no qual os animais foram avaliados exclusivamente com mistura mineral.

Foram utilizados 25 novilhos mestiços holandês $\mathrm{x}$ zebu, não-castrados, com idade e peso médios iniciais 
de 24 meses e $367,7 \mathrm{~kg}$, os quais foram distribuídos aleatoriamente entre os cinco tratamentos. Ao início do experimento, realizou-se controle de endo e ectoparasitas por intermédio da aplicação de produto à base de ivermectina (1\%). Durante o período experimental realizaram-se, quando justificados, combates contra infestação de carrapatos e mosca-do-chifre.

Os suplementos foram distribuídos diariamente, em comedouro conjunto, na quantidade de $4 \mathrm{~kg} /$ animal após as $10 \mathrm{~h}$, a fim de minimizar a interferência de efeito substitutivo sobre o comportamento de ingestão de forragem (Adams, 1985). Proporcionou-se acesso irrestrito à mistura mineral em todos os tratamentos. Esse nível de consumo, juntamente com as características apresentadas no balanceamento dos suplementos, proporcionou o fornecimento de concentrado em nível de $1 \%$ do peso vivo (PV) e o suprimento de, aproximadamente, 60, 80, 100 e 120\% das exigências de proteína bruta de um novilho nãocastrado, de raça de porte médio, com $400 \mathrm{~kg}$ de PV e ganho esperado de $1 \mathrm{~kg} /$ dia, respectivamente para os tratamentos S12, S16, S20 e S24, segundo reco- mendações do NRC (1984). A composição dos suplementos é apresentada na Tabela 1.

O ganho médio diário (GMD) foi obtido com base nos pesos vivos inicial e final avaliados após 18 horas de jejum em relação à água e alimento. Realizaram-se pesagens periódicas a cada 21 dias, com o intuito de monitorar ocorrências de distúrbios indesejáveis sobre o desempenho animal, coincidindo com a rotação de tratamentos entre piquetes, a fim de eliminar possíveis variações devidas a esta fonte, perfazendo, assim, um total de cinco períodos e 105 dias de avaliação. Os dados climáticos tomados durante o experimento, em função dos períodos experimentais, são mostrados na Tabela 2.

Ao quinto dia de cada período experimental, realizou-se coleta da massa disponível na pastagem através do corte, no nível do solo, de cinco áreas, delimitadas por um quadrado metálico de $0,5 \times 0,5 \mathrm{~m}$, escolhidas aleatoriamente dentro de cada piquete. Após a pesagem, as amostras de cada piquete foram homogeneizadas, das quais se retirou uma alíquota, a qual foi destinada à avaliação dos teores de matéria seca e proteína bruta, segundo AOAC (1990).

Tabela 1 - Proporções de ingredientes, teores de nutrientes digestíveis totais (NDT) e proteína bruta (PB), com base na matéria natural, e requerimentos de PB atendidos para os diferentes tratamentos

Table 1 - Proportion of ingredients, contents of total digestible nutrients (TDN) and crude protein (CP), as fed basis, and supplied requirements of $C P$, according to the treatments

\begin{tabular}{|c|c|c|c|c|c|}
\hline \multirow[b]{2}{*}{ Itens } & \multicolumn{5}{|c|}{$\begin{array}{c}\text { Tratamentos } \\
\text { Treatments }\end{array}$} \\
\hline & SAL & $\mathrm{S} 12$ & $\mathrm{~S} 16$ & $\mathrm{~S} 20$ & $\mathrm{~S} 24$ \\
\hline Fuháde milho & - & 0522 & $\begin{array}{l}\text { orções } \\
\text { prtions } \\
8339\end{array}$ & 7140 & 5966 \\
\hline Grounded corn grain & & & & & \\
\hline $\begin{array}{l}\text { Grão de soja inteiro } \\
\text { Whole soybean seed }\end{array}$ & - & 2,63 & 14,07 & 25,59 & 37,03 \\
\hline $\mathrm{U} / \mathrm{SA}(9: 1)^{1}$ & - & 1,15 & 1,54 & 1,92 & 2,31 \\
\hline Mistura mineral $^{2}$ & 100,0 & 1,00 & 1,00 & 1,00 & 1,00 \\
\hline Mineral mixture ${ }^{2}$ & \multicolumn{5}{|c|}{$\begin{array}{l}\text { Composição e requerimento } \\
\text { Composition and requirement }\end{array}$} \\
\hline $\begin{array}{l}\operatorname{NDT}(\%)^{3} \\
\operatorname{TDN}(\%)^{3}\end{array}$ & 0 & 77,6 & 77,8 & 78,0 & 78,3 \\
\hline $\begin{array}{l}\mathrm{PB}(\%) \\
C P(\%)\end{array}$ & 0 & 12 & 16 & 20 & 24 \\
\hline $\begin{array}{l}\text { PB atendida }(\%)^{3} \\
\text { Supplied } C P(\%)^{3}\end{array}$ & 0 & 60 & 80 & 100 & 120 \\
\hline
\end{tabular}

${ }^{1}$ Uréia: Sulfato de amônia (Urea: Ammonium sulfate).

${ }^{2}$ Composição percentual: fosfato bicálcico, 48,61; cloreto de sódio, 48,61; sulfato de zinco, 1,46; sulfato de cobre 0,72; sulfato de magnésio, 0,50; sulfato de cobalto, 0,05; e iodato de potássio, 0,05 (Percentage composition: dicalcium phosphate, .48.61; sodium chloride, 48.61; zinc sulfate, 1.46; copper sulfate, .72; magnesium sulfate. .50; cobalt sulfate, .05; potassium iodate, .05).

${ }^{3}$ Estimado segundo valores do NRC (1984) (Estimated from NRC [1984] tables). 
Ao final do período de avaliação, os animais foram abatidos por dessensibilização via concussão cerebral, seguida de secção da veia jugular, sendo avaliado o peso de carcaça (PC). Após 24 horas de resfriamento, retirou-se, de cada meia-carcaça esquerda, a seção compreendida entre a $9^{a}$ e $11^{a}$ costelas, denominada seção $\mathrm{H} \& \mathrm{H}$, a qual permitiu a estimação da composição média de carcaça em termos de tecidos muscular, adiposo e ósseo, segundo método descrita por Hankins \& Howe (1946). O rendimento de carcaça foi expresso pela razão entre o peso de carcaça quente e peso vivo final em jejum (PVF).

Durante todo o período de avaliação, foram tomadas amostras dos suplementos a cada partida produzida, formando-se, ao final, uma amostra composta proporcional, que foi submetida a análise para quantificação dos teores de matéria seca (MS), matéria orgânica $(\mathrm{MO}), \mathrm{PB}$, extrato etéreo (EE) e cinzas (AOAC, 1990); fibra em detergente neutro (FDN) e fibra em detergente ácido (FDA), com as devidas correções de procedimento para a presença de amido, e correções finais para proteínas e cinzas (Van Soest et al., 1991). O teor total de compostos nitrogenados não-protéicos foi estimado pela diferença entre nitrogênio total e nitrogênio precipitável em ácido tricloroacético (TCA), segundo adaptações de Malafaia \& Vieira (1997). A composição bromatológica dos suplementos é mostrada na Tabela 3.
Tabela 3 - Composição bromatológica dos suplementos, com base na matéria seca

Table 3 - Chemical composition of supplements in dry matter basis

\begin{tabular}{|c|c|c|c|c|}
\hline \multirow{2}{*}{$\begin{array}{l}\text { Itens }^{1} \\
\text { Item }\end{array}$} & \multicolumn{4}{|c|}{$\begin{array}{l}\text { Suplementos } \\
\text { Supplements }\end{array}$} \\
\hline & S12 & S16 & $\mathrm{S} 20$ & S24 \\
\hline$\overline{M S(\%)}$ & 87,03 & 87,34 & 87,37 & 87,68 \\
\hline$D M(\%)$ & & & & \\
\hline $\begin{array}{l}\mathrm{MO}^{2} \\
O M^{2}\end{array}$ & 978,4 & 971,4 & 966,6 & 962,4 \\
\hline $\begin{array}{l}\mathrm{PB}^{2} \\
C P^{2}\end{array}$ & 147,0 & 188,2 & 229,9 & 274,0 \\
\hline $\begin{array}{l}\mathrm{NNP}^{3} \\
N P N^{3}\end{array}$ & 50,5 & 51,2 & 56,6 & 52,9 \\
\hline $\mathrm{EE}^{2}$ & 48,3 & 62,3 & 79,6 & 84,9 \\
\hline $\begin{array}{l}\text { Cinzas }^{2} \\
\text { Ash }^{2}\end{array}$ & 21,6 & 28,6 & 33,4 & 37,6 \\
\hline $\begin{array}{l}\mathrm{CT}^{2,4} \\
T C^{2,4}\end{array}$ & 783,1 & 720,9 & 657,1 & 603,5 \\
\hline $\begin{array}{l}\mathrm{FDN}^{2} \\
N D F^{2}\end{array}$ & 74,8 & 80,0 & 87,1 & 98,8 \\
\hline $\begin{array}{l}\mathrm{CNF}^{2,5} \\
N F C^{2,5}\end{array}$ & 708,3 & 640,8 & 570,0 & 504,7 \\
\hline $\begin{array}{l}\mathrm{FDA}^{2} \\
A D F^{2}\end{array}$ & 21,7 & 36,0 & 51,9 & 65,6 \\
\hline
\end{tabular}

1/ MS - matéria seca; MO - matéria orgânica; PB - proteína bruta; NNP - compostos nitrogenados não-protéicos; EE - extrato etéreo; CT - carboidratos totais; FDN - fibra em detergente neutro; CNF - carboidratos não-fibrosos; FDA - fibra em detergente ácido. ${ }^{2} / \mathrm{g} / \mathrm{kg} \mathrm{MS.} 3 / \%$ dos compostos nitrogenados totais. $4 / \mathrm{CT}=1000-$ (PB $+\mathrm{EE}+$ Cinzas $) .5 / \mathrm{CNF}=\mathrm{CT}-\mathrm{FDN}$. $1 / D M$ - dry matter; $M O$ - organic matter; $C P$ - crude protein; NPN - nonprotein nitrogen compounds; EE-ether extract; TC-total carbohydrates; $N D F$ - neutral detergent fiber; CNF - non-fibrous carbohydrates; ADF acid detergent fiber. ${ }^{2 / \mathrm{g} / \mathrm{kg} \text { of } D M .} 3 / \%$ of total nitrogen compounds. ${ }^{4}$ $T C=1000-(C P+E E+A s h) .5 / N F C=T C-N D F$.

Tabela 2 - Precipitação total (PP), temperaturas médias máxima (Tmax) e mínima (Tmin), disponibilidade total de forragem (DTF) e teor de proteína bruta na forragem disponível (PBF), de acordo com os períodos experimentais

Table 2 - Total rainfall (TR), maximum (Tmax) and minimum (Tmin) average temperatures, total availability of forage (TAF) and crude protein level in availability forage (CPF), according to the experimental periods

\begin{tabular}{lccccc}
\hline & \multicolumn{5}{c}{$\begin{array}{c}\text { Períodos experimentais } \\
\text { Experimental periods }\end{array}$} \\
\cline { 2 - 6 } Item & 1 & 2 & 3 & 4 & 5 \\
\hline $\mathrm{PP}^{1}$ & 11,6 & 0 & 44,4 & 14,4 & 10,9 \\
$T R^{I}$ & & & & & \\
$\operatorname{Tmax}^{2}$ & 26,9 & 31,3 & 30,8 & 31,0 & 34,8 \\
$\operatorname{Tmin}^{2}$ & 12,4 & 17,6 & 17,7 & 19,5 & 20,5 \\
$\mathrm{DTF}^{3}\left(\mathrm{CV}^{4}\right)$ & $8,44(11,1)$ & $7,45(10,2)$ & $6,98(6,7)$ & $7,61(16,4)$ & $4,95(9,9)$ \\
$T A F^{3}\left(C V^{4}\right)$ & & & & & \\
$\mathrm{PBF}^{5}$ & 2,54 & 2,93 & 2,90 & 4,39 & 3,55 \\
$C P F^{4}$ & & & & & \\
\hline
\end{tabular}

$1 / \mathrm{mm} .{ }^{2} /{ }^{\circ} \mathrm{C} .3 / \mathrm{t} / \mathrm{ha} .{ }^{4} / \mathrm{CV}=$ coeficiente de variação - \% (CV = coefficient of variation - \%). $5 / \%$ MS (\% of DM). 
A avaliação de parâmetros econômicos tomou como base as receitas e despesas adicionais em relação ao tratamento controle (SAL). Para melhor visualização dos resultados, aplicou-se análise de sensibilidade, em função de variações nos valores de suplementos e venda dos animais. Todas as cotações empregadas foram tomadas na região e no período em que se conduziu este experimento.

$\mathrm{O}$ experimento foi analisado segundo delineamento inteiramente casualizado, empregando-se análise de covariância, segundo técnica descrita por Snedecor \& Cochran (1989), adotando-se como covariável o peso vivo inicial em jejum.

A comparação entre tratamentos foi realizada por intermédio da decomposição da soma de quadrados relacionada a esta fonte de variação por intermédio de contrastes ortogonais estabelecidos a priori, relativos aos efeitos de ordens linear, quadrática e cúbica $(\alpha=0,10)$. Antecipa-se que, em nenhuma das variáveis avaliadas detectou-se efeitos relativos aos níveis de proteína nos suplementos de ordem cúbica, sendo, portanto, suprimidos da discussão. No caso de não se observar efeito significativo para a covariável peso vivo inicial, o modelo foi reparametrizado, deslocando-se o grau de liberdade associado a esta fonte ao resíduo.

\section{Resultados e Discussão}

As disponibilidades médias de matéria seca e teor de proteína bruta na pastagem em função dos períodos experimentais são mostrados na Tabela 3. Observou-se disponibilidade média de matéria seca na pastagem de $7086 \pm 169 \mathrm{~kg} / \mathrm{ha}$, sendo superior à relatada por Paulino et al. (2002) $(6026 \mathrm{~kg} / \mathrm{ha})$, em condições semelhantes às apresentadas neste estudo, e considerada satisfatória para os animais exercerem pastejo irrestrito, sem entraves à capacidade seletiva.

$\mathrm{Na}$ Tabela 4, são apresentadas as médias para o ganho médio diário (GMD), peso vivo final (PFV), peso de carcaça $(\mathrm{PC})$, rendimento de carcaça (RC) e dias necessários para o alcance de $450 \mathrm{~kg}$ de $\mathrm{PV}$ (D450).

Observou-se que todos os tratamentos que receberam suplementação apresentaram desempenho superior ao grupo controle (SAL) $(\mathrm{P}<0,01)$ com relação às variáveis GMD e PVF. Ressalta-se, contudo, a limitação apresentada por esta comparação, não permitindo distinguir variações devidas ao fornecimento diferenciado de nutrientes ou efeitos associativos atribuídos à composição suplementar.

O GMD observado em SAL $(0,277 \mathrm{~kg} / \mathrm{dia})$ situou-se

Tabela 4 - Médias, coeficientes de variação (CV), níveis descritivos de probabilidade para contrastes (Valor $P$ ), estimativas para parâmetros de regressão e coeficientes de determinação $\left(r^{2} / R^{2}\right)$ para as variáveis ganho médio diário (GMD - kg), peso vivo final (PVF - kg), peso de carcaça (PC - kg), rendimento de carcaça $(R C-\%)$ e dias para o alcance de $450 \mathrm{~kg}$ de peso vivo (D450) para os diferentes tratamentos

Table 4 - Means, coefficients of variation (CV), descriptive levels of probability for contrasts ( $P$ Value), estimates for regression parameters and coefficient of determination $\left(r^{2} / R^{2}\right)$ for variables average daily gain $(A D G-k g)$, final live weight (FLW - $\mathrm{kg})$, carcass weight $(C W-\mathrm{kg})$, carcass dressing percentage $(C D P)$ and necessary days to reach $450 \mathrm{~kg}$ of live weight (D450), according to the treatments

\begin{tabular}{|c|c|c|c|c|c|c|c|c|c|c|c|c|c|}
\hline \multirow[b]{2}{*}{ Item } & \multicolumn{4}{|c|}{$\begin{array}{c}\text { Tratamentos } \\
\text { Treatments }\end{array}$} & \multicolumn{4}{|c|}{$\begin{array}{l}\text { Valor } \mathrm{P}^{2} \\
P \text { Value }\end{array}$} & \multicolumn{4}{|c|}{$\begin{array}{c}\text { Estimativas dos parâmetros } \\
\text { da regressão } \\
\text { Estimates of regression } \\
\text { parameters } \\
\end{array}$} & \multirow[b]{2}{*}{$\mathrm{r}^{2} / \mathrm{R}^{2}$} \\
\hline & SAL & $\mathrm{S} 12$ & S16 & $\mathrm{S} 20$ & $\mathrm{~S} 24$ & C vs. S & $\mathrm{L}$ & Q & $\mathrm{CV}(\%)$ & $\mathrm{b}_{0}$ & $\mathrm{~b}_{1}$ & $\mathrm{~b}_{2}$ & \\
\hline $\begin{array}{l}\text { GMD } \\
A D G\end{array}$ & 0,277 & 0,684 & 0,811 & 0,983 & 0,800 & 0,0001 & 0,0850 & 0,0250 & 20,1 & $-0,8879$ & 0,1875 & $-0,0048$ & 0,8263 \\
\hline $\begin{array}{l}\mathrm{PVF}^{1} \\
F L W^{1}\end{array}$ & 397,4 & 440,8 & 453,8 & 471,9 & 453,1 & 0,0001 & 0,0866 & 0,0313 & 3,4 & 279,102 & 19,2622 & $-0,4969$ & 0,8210 \\
\hline $\begin{array}{l}\mathrm{PC}^{1} \\
W C^{1}\end{array}$ & 200,0 & 228,3 & 235,5 & 242,1 & 241,7 & 0,0001 & 0,0521 & 0,4563 & 5,0 & 215,739 & 1,1783 & - & 0,8663 \\
\hline $\begin{array}{l}\mathrm{RC} \\
C D P\end{array}$ & 50,28 & 51,73 & 52,00 & 51,31 & 53,32 & 0,0989 & 0,3453 & 0,3689 & 4,1 & 52,09 & - & - & - \\
\hline D450 ${ }^{1}$ & 312,4 & 117,4 & 103,1 & 84,3 & 105,4 & 0,0001 & 0,1236 & 0,0523 & 16,9 & 295,6 & $-21,3126$ & 0,5539 & 0,8239 \\
\hline
\end{tabular}

\footnotetext{
${ }^{1}$ Médias ajustadas por covariância.

${ }^{2} \mathrm{C}$ vs. S - controle (SAL) vs. suplementos; L e $Q$ - efeitos linear e quadrático para níveis de proteína bruta nos suplementos, respectivamente.

${ }^{1}$ Means were adjusted by covariance analysis.

${ }^{2} \mathrm{C}$ vs. S-control treatment (SAL) vs. supplemented treatments; $L$ and $Q$ - linear and quadratic effects of crude protein levels in the supplements, respectively.
} 
aquém do desejado para terminação de animais ainda no período seco, propiciando PVF de $397,38 \mathrm{~kg}$ (Tabela 4), o que implica na manutenção dos animais na propriedade por, ao menos, parte da estação chuvosa subseqüente para que se alcance peso satisfatório de abate, o que não pode ser proveitoso em muitos sistemas que enfocam a pecuária de ciclo curto a pasto. Projeção numérica deste comportamento foi observada sobre a variável D450, que apresentou grande discrepância entre animais controle $(\mathrm{SAL})$ e aqueles suplementados $(\mathrm{P}<0,01)$ (Tabela 4). Ressalta-se, contudo, que esta comparação, embora esclarecedora do ponto de vista produtivo, deve ser interpretada com cautela, uma vez que a média para D450 observada em SAL extrapolou o período experimental, não havendo, portanto, garantia da exatidão desta estimativa, embora o valor de PVF observado para SAL permita, com certeza, afirmar a existência desta discrepância.

Recorrendo-se aos demais contrastes para detecção de relação funcional entre a composição de suplementos e as variáveis resposta em questão, observou-se comportamento quadrático para as variáveis GMD $(\mathrm{P}<0,03)$ e PVF $(\mathrm{P}<0,04)$ (Tabela 4$)$, com pontos críticos (resposta máxima) obtidos sobre os níveis protéicos de $19,53(0,943 \mathrm{~kg} / \mathrm{dia})$ e $19,38 \%$ $(465,8 \mathrm{~kg})$, respectivamente. Como reflexo do comportamento destas variáveis, observou-se efeito quadrático em D450 $(\mathrm{P}<0,06)$ (Tabela 4), apresentando mínima resposta sobre o nível de $19,22 \%$ PB (90,6 dias).

Dentro do contexto da nutrição de bovinos em pastejo, sob as óticas produtiva e econômica, a otimização da produtividade animal deve agregar, em primeiro plano, à identificação e suplementação do nutriente em limitação primária (Klopfenstein, 1996). Com a chegada da estação seca, as pastagens tropicais decrescem rapidamente em digestibilidade e, particularmente, em conteúdo total de nitrogênio, o que leva à perda excessiva de produtividade, constituindo o principal fator limitante à produção animal (Leng, 1984).

Neste enfoque, dá-se suporte ao comportamento de melhoria de desempenho, medido sobre as variáveis GMD, PVF e D450 (Tabela 4), com a elevação do nível protéico suplementar de 12 a $20 \%$, em função da natureza prioritária ou de limitação primária da proteína no período seco, uma vez observada pequena variação sobre o conteúdo energético dos suplementos (Tabela 1).

Forragens de baixa qualidade apresentam deficiência não só em nutrientes para o desempenho animal, mas também em substratos para o metabolismo microbiano - neste caso, principalmente, compostos nitrogenados - fazendo com que a inclusão de suplementos protéicos à dieta apresente efeito benéfico sobre o ambiente ruminal (Dixon \& Stockdale, 1999), ampliando-se a síntese total de compostos nitrogenados microbianos, a extração de energia a partir dos carboidratos fibrosos da forragem (Leng, 1990; Hannah et al., 1991; e Paulino et al., 2001) e o aproveitamento dos substratos energéticos do próprio suplemento, que resulta em maior aporte de nutrientes para o intestino e ácidos graxos voláteis para o metabolismo energético.

Em adição, embora sob níveis elevados de suplementação, como apresentados neste estudo, obtenha-se efeito substitutivo sobre o consumo de forragem, em comparação a animais não-suplementados (NRC, 1984; DelCurto et al., 1990a; 1990b; e Santos, 2001), este efeito tende a ser amenizado com a elevação do teor de PB nos suplementos (Hannah et al., 1991), o que, em conjunto aos aspectos digestivos discutidos anteriormente, suporta, de forma mais concreta, o comportamento produtivo observado.

De forma contrária aos aspectos discutidos sobre a natureza prioritária da proteína nas condições em que se conduziu este experimento, o comportamento quadrático observado para as variáveis GMD, PVF e D450 (Tabela 4), indicou redução no desempenho animal sob o nível protéico suplementar de $24 \%$. Esta queda no desempenho pode, em parte, ser justificada pela possível ocorrência de excesso de proteína para o metabolismo microbiano/animal, o qual pode ser perdido por via urinária na forma de uréia. A síntese de uma molécula de uréia a nível hepático apresenta balanço negativo de 1 ATP (Brody, 1993), o que pode acarretar, no caso de excesso, em dreno energético, prejudicando o desempenho animal (NRC, 1988). Por outro lado, em alguns casos, embora a energia requerida para síntese de uréia não represente elevada proporção da energia digestível total ingerida, o fato de este dispêndio energético ser concentrado quase que exclusivamente sobre o fígado (Chalupa et al., 1970), pode causar competição por ATP com a via gliconeogênica do propionato (NRC, 1988). Depressões nas concentrações hepáticas de NADH, NADP e NADPH são relacionadas à elevação do nível hepático de amônia e síntese de uréia sob excesso protéico dietético, o que gera distúrbios sobre o metabolismo intermediário dos carboidratos (Chalupa et al., 1970; Prior et al., 1970; NRC, 1988). 
Em outro aspecto, a energia necessária para a formação de uréia a partir do excesso de proteína decresce a razão energia líquida/energia metabolizável, sendo direcionada à formação de calor corporal (NRC, 1988). Segundo Poppi \& McLennan (1995), a dissipação de calor corporal constitui grande limitação para a produção de bovinos nos trópicos, fazendo com que os animais, mesmo não demonstrando os sintomas óbvios deste estresse, passem a restringir o consumo, como ferramenta para redução do metabolismo, de forma a adequar a produção de calor corporal a taxas na qual este possa ser dissipado confortavelmente. Por intermédio da união destas afirmações pode-se inferir que reduções no consumo podem ser observadas em animais suplementados com proteína em excesso. Esta suposição é suportada pelos resultados apresentados por DelCurto et al. (1990a) e (1990b) que encontraram redução no consumo de forragem por novilhos suplementados em nível de 0,4 e $0,5 \%$ PV ao elevarem o nível protéico suplementar de 28 a $41 \%$ e de 25 a $39 \%$, respectivamente; embora ampliações no consumo de forragem tenham sido observadas pela elevação dos níveis de PB dos suplementos de 12 a $28 \%$ e de 13 a $25 \%$.

Não foram observadas diferenças significativas entre suplementos para a variável RC $(\mathrm{P}>0,10)$ (Tabela 4), obtendo-se valor médio de 52,09\%. Simi- laridade à média obtida neste estudo foi relatada por Paulino et al. (2002) (52,96\%) ao abaterem animais mestiços em condições de pastagem e suplementos (20\% PB) similares às aqui apresentadas. Estes autores, ao compararem a estimativa obtida a valores da literatura, inferiram que, em termos de RC, animais terminados a pasto com suplementação apresentam desempenho semelhante àqueles terminados em condições de confinamento.

Contraditoriamente às variáveis GMD, PVF e D450, o desempenho produtivo medido por intermédio da variável PC mostrou elevação linear com a ampliação do nível protéico dos suplementos $(\mathrm{P}<0,06)$, embora os tratamentos S20 e S24 tenham apresentado médias similares $(242,9$ e $241,7 \mathrm{~kg}$, respectivamente) (Tabela 4). Ressalta-se que o fornecimento de suplementos permitiu desempenho superior sobre SAL $(\mathrm{P}<0,01)$ (Tabela 4).

A composição física de carcaça, em termos de tecidos muscular (TM), adiposo (TA) e ósseo (TO), é apresentada na Tabela 5. Não se observaram efeitos significativos com relação à composição de suplementos $(\mathrm{P}>0,10)$ sobre estas variáveis; observando-se, contudo, diferenças entre SAL e suplementos com relação à proporção de $\mathrm{TA}(\mathrm{P}<0,09) \mathrm{e}$ TO $(\mathrm{P}<0,01)$.

De forma geral, o valor médio obtido para TA

Tabela 5 - Médias, coeficientes de variação (CV), níveis descritivos de probabilidade para contrastes (Valor P), estimativas para parâmetros de regressão e coeficientes de determinação $\left(r^{2} / R^{2}\right)$ para as variáveis percentagem de tecidos muscular (TM), adiposo (TA) e ósseo (TO) na carcaça e índice produtivo industrial (IPIN) para os diferentes tratamentos

Table 5 - Means, coefficients of variation (CV), descriptive levels of probability for contrasts (P Value), estimates for regression parameters and coefficient of determination $\left(r^{2} / R^{2}\right)$ for percentage of muscular (MT), bone (BT) and fatty (FT) tissues in the carcass and productive industrial index (PII), according to the treatments

\begin{tabular}{|c|c|c|c|c|c|c|c|c|c|c|c|c|c|}
\hline \multirow[b]{2}{*}{ Item } & \multicolumn{4}{|c|}{$\begin{array}{l}\text { Tratamentos } \\
\text { Treatments }\end{array}$} & \multicolumn{4}{|c|}{$\begin{array}{l}\text { Valor } \mathrm{P}^{2} \\
P \text { value }\end{array}$} & \multirow[b]{2}{*}{$\mathrm{CV}(\%)$} & \multicolumn{3}{|c|}{$\begin{array}{c}\text { Estimativas dos parâmetros } \\
\text { da regressão } \\
\text { Estimates of regression } \\
\text { parameters }\end{array}$} & \multirow[b]{2}{*}{$\mathrm{r}^{2} / \mathrm{R}^{2}$} \\
\hline & SAL & $\mathrm{S} 12$ & S16 & S20 & $\mathrm{S} 24$ & C vs. S & $\mathrm{L}$ & Q & & $\mathrm{b}_{0}$ & $\mathrm{~b}_{1}$ & $\mathrm{~b}_{2}$ & \\
\hline $\begin{array}{l}\text { TM } \\
M T\end{array}$ & 63,98 & 63,19 & 63,13 & 63,19 & 64,07 & 0,7158 & 0,6731 & 0,7455 & 5,0 & 63,40 & - & - & - \\
\hline $\begin{array}{l}\text { TA } \\
F T\end{array}$ & 15,28 & 18,15 & 18,16 & 18,14 & 18,52 & 0,0884 & 0,8698 & 0,9021 & 18,7 & 18,24 & - & - & - \\
\hline $\begin{array}{l}\text { TO } \\
B T\end{array}$ & 20,74 & 18,58 & 18,70 & 18,67 & 17,45 & 0,0003 & 0,1332 & 0,1867 & 5,8 & 18,35 & - & - & - \\
\hline $\begin{array}{l}\text { IPIN }^{1} \\
P I I^{1}\end{array}$ & - & 1,605 & 1,814 & 2,092 & 1,810 & - & 0,0931 & 0,0432 & 13,7 & $-0,9038$ & 0,2986 & $-0,0077$ & 0,8348 \\
\hline
\end{tabular}

\footnotetext{
${ }^{1}$ Função discriminante linear de Fisher $=1,580934$ x Ganho médio diário $+0,014647$ x Porcentagem de gordura na carcaça $+0,001129$ $x$ Peso de carcaça.

${ }^{2} \mathrm{C}$ vs. $\mathrm{S}$ - controle (SAL) vs. suplementos; L e $\mathrm{Q}$ - efeitos linear e quadrático para níveis de proteína bruta nos suplementos, respectivamente.

${ }^{1}$ Fisher discriminate linear function $=1.580934 x$ Average daily gain $+.014647 \times$ Percentage of fatty tissue in the carcass $+.001129 \times$ Carcass weight.

${ }^{2}$ C vs. S - control treatment (SAL) vs. supplemented treatments; L e Q-linear and quadratic effects of crude protein levels in the supplements, respectively.
} 
com o fornecimento de suplementos $(18,4 \%)$ mostrou-se aquém do relatado em animais confinados (Gesualdi Jr. et al., 2000), sendo, no entanto, semelhante à avaliação realizada em animais terminados em condições similares às empregadas neste estudo (Santos, 2001). Ressalta-se que as carcaças de todos os animais foram qualificadas como escassas em gordura ao momento do abate. Este comportamento reflete, possivelmente, $o$ fato de os animais empregados neste estudo serem não-castrados, o que pode comprometer substancialmente a deposição de gordura na carcaça (Berg \& Butterfield, 1979; Restle et al., 1994), podendo ser ressaltado pelo nível de sangue holandês apresentado pelos animais, o que confere menores proporções de tecido adiposo na carcaça em comparação a raças características de corte (Jorge et al., 1997). Por outro lado, animais em pastejo apresentam acréscimo na ordem de 10 a $20 \%$ nas exigências de energia para mantença (CSIRO, 1990), o que poderia, possivelmente, afetar a partição de energia para a deposição de tecidos.

Por outro lado, as diferenças observadas entre SAL e os demais tratamentos com relação às variáveis TA e TO (Tabela 5) obtêm suporte sobre o comportamento observado sobre GMD (Tabela 4), no sentido de que animais de plano nutricional mais elevado, proporcionado pelo fornecimento de suplementos, apresentam maior intensidade de crescimento, o que resulta em menores proporções de ossos (Müller \& Primo, 1986; Gesualdi Jr. et al., 2000) e maior teor de tecido adiposo (Berg \& Butterfield, 1979) na carcaça. De outra forma, o maior percentual de TA observado na carcaça dos animais suplementados constitui possível causa da superioridade em relação a SAL quanto ao $\mathrm{RC}(\mathrm{P}<0,10)$ (Tabela 4), uma vez que este representa o componente da carcaça com maior influência sobre esta variável (Berg \& Butterfield, 1979).

Em virtude da discrepância inferencial sobre o desempenho produtivo encontrada entre $\mathrm{PC}$ e as variáveis GMD, PVF e D450, adotou-se, como ferramenta de diagnóstico para melhor discriminação entre tratamentos que envolveram suplementação, o emprego da técnica de análise multivariada denominada Função Discriminante Linear de Fisher (FDLF) ou primeira variável canônica (Harris, 1975), na qual empregaram-se as variáveis GMD, $\mathrm{PC}$ e TA, as quais foram combinadas por otimização linear em uma única variável, aqui denominada Índice Produtivo Industrial (IPIN). A escolha desta combinação se deu com base na importância apresentada pelas variáveis GMD e $\mathrm{PC}$ ao produtor, englobando, do ponto de vista industrial, além do PC, a variável TA, a qual representa, entre as medidas tomadas neste estudo, a de maior relação ao grau de acabamento de carcaças em enfoque comercial.

Os resultados obtidos para o IPIN são apresentados na Tabela 5. O autovalor associado à FDLF apresentou importância relativa de $85,81 \%$, o que garante bom poder discriminante e maximização do teste $\mathrm{F}$ para tratamentos pela utilização do autovetor canônico correspondente a este autovalor. Observou-se comportamento quadrático $(\mathrm{P}<0,05)$ para $\mathrm{o}$ IPIN entre suplementos (Tabela 5), com ponto de máxima resposta situado sobre o nível protéico suplementar de 19,39\%. Desta forma, embora apresentando comportamento linear para a variável PC, a avaliação conjunta com GMD e TA não permitiu apontar resultados favoráveis à elevação do nível de $\mathrm{PB}$ a S24, conforme demonstrado univariadamente para GMD, PVF e D450 (Tabela 4).

Os indicadores econômicos de produção, com base diária, são apresentados na Tabela 6. Ressalta-se que os índices apresentados retratam a diferença entre os custos e benefícios obtidos com a suplementação de forma diferencial ao tratamento controle (SAL). Segundo os resultados apresentados (Tabela 6), observou-se, em termos diários, retorno positivo somente sobre o tratamento S20, sendo, mesmo assim, de baixa magnitude $(1,01 \%)$; ao passo que os demais tratamentos apresentaram, sem exceção, indicadores negativos. Deve-se ressaltar, contudo, que esta comparação não permite visualizar as variações obtidas com a antecipação do abate dos animais, a qual consiste em um dos principais benefícios em sistemas de suplementação a pasto (Euclides et al., 1998). Para que isto se tornasse possível, optou-se por interpretar os indicadores econômicos sobre a projeção de D450, o que permitiu avaliar o dispêndio total com insumos e o benefício gerado pela antecipação na liberação da pastagem (Tabela 7).

Euclides et al. (2001) alertaram que cautela seria necessária na interpretação de resultados desta natureza em função do ganho compensatório que poderia ser apresentado por animais que permanecessem em desempenho durante o período de chuvas subseqüente, o que concorda à projeção de D450 para SAL (Tabela 4). Dessa forma, adotou-se a pressuposição de que os animais provenientes do tratamento SAL manteriam seu nível de $\operatorname{GMD}(0,277 \mathrm{~kg} /$ dia $)$ até $31 / 10$, 
Tabela 7 - Indicadores econômicos de produção, por animal, para os diferentes suplementos, em função do total necessário em suplementação e ocupação de pastagem para o alcance de $450 \mathrm{~kg}$ de peso vivo (D450)

Table 7 - Economic indicators of production, in animal basis, in function of pasture occupation and total supplementation to reach $450 \mathrm{~kg}$ of live weight (D450)

\begin{tabular}{|c|c|c|c|c|}
\hline \multirow[b]{2}{*}{ Item } & \multicolumn{4}{|c|}{$\begin{array}{l}\text { Suplementos } \\
\text { Supplements }\end{array}$} \\
\hline & S12 & S16 & S20 & $\mathrm{S} 24$ \\
\hline \multicolumn{5}{|l|}{ Ganho diferencial (kg/dia) } \\
\hline Differential gain (kg/day) & 0,407 & 0,534 & 0,705 & 0,523 \\
\hline D450 & 117,4 & 103,1 & 84,3 & 105,4 \\
\hline Custo total suplementação (R\$) & & & & \\
\hline $\begin{array}{l}\text { Total supplement expense }(R \$) \\
\text { Ganho em ocupação (dias) }\end{array}$ & 102,20 & 95,93 & 83,51 & 110,73 \\
\hline $\begin{array}{l}\text { Occupation gain (days) } \\
\text { Ganho em ocupação }(\mathrm{R} \$ / \mathrm{cab})^{2}\end{array}$ & 62,6 & 76,9 & 95,7 & 74,6 \\
\hline $\begin{array}{l}\text { Occupation gain }(R \$ / \text { animal })^{2} \\
\text { Ganho sobre controle }(\mathrm{kg})\end{array}$ & 10,43 & 12,82 & 15,95 & 12,43 \\
\hline $\begin{array}{l}\text { Gain on control treatment }(\mathrm{kg}) \\
\text { Ganho sobre controle }(\mathrm{R} \$)^{3}\end{array}$ & 47,8 & 55,1 & 59,4 & 55,1 \\
\hline $\begin{array}{l}\text { Gain on control treatment }(R \$)^{3} \\
\text { Retorno sem benefício pasto }(\mathrm{R} \$ / \mathrm{cab})\end{array}$ & 68,03 & 78,39 & 84,62 & 78,49 \\
\hline $\begin{array}{l}\text { Income without pasture benefit (R\$/animal) } \\
\text { Retorno com benefício pasto }(\mathrm{R} \$ / \mathrm{cab})\end{array}$ & $-34,17$ & $-17,54$ & 1,11 & $-32,24$ \\
\hline Income with pasture benefit (R\$/animal) & $-23,74$ & $-4,73$ & 17,06 & $-19,81$ \\
\hline
\end{tabular}

${ }^{1}$ Considerando média de ganho para o tratamento controle de 0,277 kg/dia até 31/10/2000, e assumindose taxa de ganho de $0,800 \mathrm{~kg} / \mathrm{dia}$ a partir de 01/11/2000.

${ }^{2}$ Valor comercial de aluguel de pastagem assumido como custo de oportunidade (R $\$ 5,00 / \mathrm{cab} / \mathrm{mês}$ ).

${ }^{3}$ Considerando rendimento de carcaça médio (52,09\%). Valor de venda (arroba): R\$ 41,00 (Outubro/ 2000).

1 The average daily gain of control treatment (SAL) was considered $0.277 \mathrm{~kg} /$ day from begin of experiment to 10/31/2002 and $0.800 \mathrm{~kg} /$ day from $11 / 01 / 2002$.

${ }^{2}$ Rent value of pasture was assumed as opportunity cost ( $R \$ 5.00 /$ animal/month).

${ }^{3}$ Average carcass dressing percentage (52.09\%). Sale value: $R \$ 41.00 / 15 \mathrm{~kg}$ of carcass (October/2000).

Tabela 8 - Análise de sensibilidade, por animal, para o retorno bruto $(R \$)$, calculado em função do necessário para o alcance de $450 \mathrm{~kg}$ de peso vivo, de acordo com variações nos valores comerciais de suplementos e vendas de animais

Table 8 - Sensibility analysis, as animal basis, for crude income ( $R \$)$, calculated as function of necessary to reach $450 \mathrm{~kg}$ of live weight, according to the values of supplements and sale of animals

\begin{tabular}{cc|cccc}
\hline \multicolumn{2}{c|}{$\begin{array}{c}\text { Variações } \\
\text { Variations }\end{array}$} & \multicolumn{3}{c}{$\begin{array}{c}\text { Tratamentos } \\
\text { Treatments }\end{array}$} \\
\hline $\begin{array}{c}\text { Venda de } \\
\text { animais } \\
\text { Sale of }\end{array}$ & $\begin{array}{c}\text { Custo de } \\
\text { suplementos } \\
\text { animals }\end{array}$ & $\begin{array}{c}\text { Supplement } \\
\text { expense }\end{array}$ & $\mathrm{S} 12$ & $\mathrm{~S} 16$ & $\mathrm{~S} 20$ \\
\hline $0 \%$ & $0 \%$ & $-23,74$ & $-4,73$ & 17,06 & $-19,81$ \\
$+2,5 \%$ & $0 \%$ & $-22,04$ & $-2,77$ & 19,17 & $-17,85$ \\
$+5 \%$ & $0 \%$ & $-20,34$ & $-0,81$ & 21,29 & $-15,89$ \\
$0 \%$ & $-5 \%$ & $-18,63$ & 0,07 & 21,23 & $-14,27$ \\
$+2,5 \%$ & $-5 \%$ & $-16,93$ & 2,03 & 23,35 & $-12,31$ \\
$+5 \%$ & $-5 \%$ & $-15,23$ & 3,99 & 25,46 & $-10,35$ \\
$0 \%$ & $-10 \%$ & $-13,52$ & 4,87 & 25,41 & $-8,74$ \\
$+2,5 \%$ & $-10 \%$ & $-11,82$ & 6,83 & 27,52 & $-6,77$ \\
$+5 \%$ & $-10 \%$ & $-10,12$ & 8,79 & 29,64 & $-4,81$ \\
$0 \%$ & $-15 \%$ & $-8,41$ & 9,66 & 29,58 & $-3,20$ \\
$+2,5 \%$ & $-15 \%$ & $-6,71$ & 11,62 & 31,70 & $-1,24$ \\
$+5 \%$ & $-15 \%$ & $-5,01$ & 13,58 & 33,81 & 0,72 \\
\hline
\end{tabular}

R. Bras. Zootec., v.33, n.1, p.169-180, 2004 
maioria dos casos, além das possibilidades do produtor e, embora algum escalonamento possa ser realizado, a manutenção de animais na propriedade, com o intuito de se aguardar alterações favoráveis no mercado, pode não possibilitar bons retornos, em virtude do aumento das exigências de mantença e ganho dos animais, o que compromete a eficiência de utilização dos alimentos, e do retardamento da liberação das pastagens para novos lotes de animais. Por outro lado, por intermédio de processo de armazenagem, a aquisição de insumos em períodos de alta oferta e, conseqüentemente, menor preço, pode incrementar de maneira satisfatória a lucratividade do sistema.

\section{Conclusões}

O nível protéico em suplementos múltiplos para terminação de bovinos em pastagens de Brachiaria decumbens durante a época seca deve estar entre 19 e $20 \%$, o que permite otimizar o desempenho produtivo animal.

Em termos econômicos, a adoção do nível de $20 \%$ de proteína bruta nos suplementos permite rentabilidade favorável em animais terminados durante o período da seca, a qual pode ser incrementada se adotado esquema de aquisição estratégica de insumos.

\section{Literatura Citada}

ADAMS, D.C. Effect of time of supplementation on performance, forage intake and grazing behavior of yearling beef steers grazing russian wild ryegrass in the fall. Journal of Animal Science, v.61, n.4, p.1037-1042, 1985.

ASSOCATION OF OFFICIAL ANALYTICAL CHEMISTRY - AOAC. Official methods of analysis. 15.ed. Arlington, 1990. $1117 \mathrm{p}$.

BERG, R.T.; BUTTERFIELD, R.M. Nuevos conceptos sobre desarrollo de ganado vacuno. Zaragoza: Acribia, 1979. $207 p$.

BRODY, T. Nutritional biochemistry. San Diego: Academic Press, 1993. 658p.

CHALUPA, W.; CLARK, J.; OPLIGER, P. et al. Detoxication of ammonia in sheep fed soy protein or urea. Journal of Nutrition, v.100, n.1, p.170-176, 1970.

COMMONWEALTH SCIENTIFIC AND INDUSTRIAL RESEARCH ORGANIZATION - CSIRO. Feeding standards for Australian livestock. Ruminants. Melbourne: Print Advisory Service Melbourne, 1990. 266p.

DelCURTO, T.; COCHRAN, R.C.; HARMON, D.L. et al. Supplementation of dormant Tallgrass-Prarie forage: I. Influence of varying supplemental protein and (or) energy levels on forage utilization characteristics of beef steers in confinement. Journal of Animal Science, v.68, n.2, p.515531, 1990a.

DelCURTO, T.; COCHRAN, R.C.; CORAH, L.R. et al.
Supplementation of dormant Tallgrass-Prarie forage: II. Performance and forage utilization characteristics in grazing beef cattle receiving supplements of different protein concentrations. Journal of Animal Science, v.68, n.2, p.532-542, $1990 \mathrm{~b}$.

DIXON, R.M.; STOCKDALE, C.R. Associative effects between forages and grains: consequences for feed utilization. Australian Journal of Agricultural Research, v.50, n.3, p.757-773, 1999.

EUCLIDES, V.P.B.; EUCLIDES FILHO, K.; ARRUDA, Z.J. et al. Desempenho de novilhos em pastagens de Brachiaria decumbens submetidos a diferentes regimes alimentares. Revista Brasileira de Zootecnia, v.27, n.2, p.246-254, 1998.

EUCLIDES, V.P.B.; EUCLIDES FILHO, K.; COSTA, F.P. et al. Desempenho de novilhos F1 angus-nelore em pastagens de Brachiaria decumbens submetidos a diferentes regimes alimentares. Revista Brasileira de Zootecnia, v.30, n.2, p.470-481, 2001.

GESUALDI JR., A.; PAULINO, M.F.; VALADARES FILHO, S.C. et al. Níveis de concentrado na dieta de novilhos F1 limousin x nelore: características de carcaça. Revista Brasileira de Zootecnia, v.29, n.5, p.1467-1473, 2000.

HANKINS, O.G.; HOWE, P.E. Estimation of the composition of beef carcasses and cuts. Technical Bulletin $n^{\circ}$ 926, Washington, D.C.: Department of Agriculture, 1946. 20p.

HANNAH, S.M.; COCHRAN, R.C.; VANZANT, E.S. et al. Influence of protein supplementation on site and extent of digestion, forage intake, and nutrient flow characteristics in steers consuming dormant Bluestem-Range forage. Journal of Animal Science, v.69, n.6, p.2624-2633, 1991.

HARRIS, R.J. A primer of multivariate statistics. New York: Academic Press, 1975. 332p.

JORGE, A.M.; FONTES, C.A.A.; SOARES, J.E. et al. Características de carcaça de bovinos e bubalinos abatidos em diferentes estádios de maturidade. Revista Brasileira de Zootecnia, v.26, n.5, p.1039-1047, 1997.

KLOPFENSTEIN, T. Need for escape protein by grazing cattle. Animal Feed Science and Technology, v.60, n.1, p.191199, 1996.

LENG, R.A. Supplementation of tropical and subtropical pastures for ruminant production. In: GILCHRIST, F.M.C.; MACKIE, R.I. (Eds.) Herbivore nutrition in the subtropics and tropics. Craighall, South Africa: The Science Press Ltda, 1984. p.129-144.

LENG, R.A. Factors affecting the utilization of "poor-quality" forages by ruminants particularly under tropical conditions. Nutrition Research and Review, v.3, n.3, p.277-303, 1990.

MALAFAIA, P.A.M.; VIEIRA, R.A.M. Técnicas de determinação dos compostos nitrogenados em alimentos para ruminantes. In: DIGESTIBILIDADE EM RUMINANTES, 1997, Lavras. Anais... Lavras: FAEP, 1997. p.29-54.

MÜLLER, L.; PRIMO, A.T. Influência do regime alimentar no crescimento e terminação de bovinos e na qualidade da carcaça. Pesquisa Agropecuária Brasileira, v.21, n.4, p.445-452, 1986.

NATIONAL RESEARCH COUNCIL - NRC. Nutrient requirements of beef cattle. 6.ed. Washington, D.C.: Academic Press, 1984. 90p.

NATIONAL RESEARCH COUNCIL - NRC. Nutrient requirements of dairy cattle. 6.ed. Washington, D.C.: Academic Press, 1988. 158p.

PAULINO, M.F. Suplementação de bovinos em pastejo. 
Informe Agropecuário, v.21, n.205, p.96-106, 2000.

PAULINO, M.F.; DETMANN, E.; ZERVOUDAKIS, J.T. Suplementos múltiplos para recria e engorda de bovinos em pastejo. In: SIMPÓSIO DE PRODUÇÃO DE BOVINOS DE CORTE, 2., 2001, Viçosa, MG. Anais... Viçosa, MG: Universidade Federal de Viçosa, 2001. p.187-232.

PAULINO, M.F.; DETMANN, E.; VALADARES FILHO, S.C. et al. Soja grão e caroço de algodão em suplementos múltiplos para terminação de bovinos mestiços em pastejo. Revista Brasileira de Zootecnia, v.31, n.1, 484-491, 2002 (suplemento).

POPPI, D.P.; McLENNAN, S.R. Protein and energy utilization by ruminants at pasture. Journal of Animal Science, v.73, n.1, p.278-290, 1995.

PRIOR, R.L.; CLIFFORD, A.J.; HOGUE, D.E. et al. Enzymes and metabolites of intermediary metabolism in urea-fed sheep. Journal of Nutrition, v.100, n.2, p.438-444, 1970.

RESTLE, J.; GRASSI, C.; FEIJÓ, G.L.D. Características de carcaça de bovinos de corte inteiros ou castrados em diferentes idades. Pesquisa Agropecuária Brasileira, v.29, n.10, p.1603-1607, 1994.
SANTOS, E.D.G. Terminação de bovinos em pastagem de Brachiaria decumbens Stapf, durante a estação seca, alimentados com diferentes concentrados. Viçosa, MG: Universidade Federal de Viçosa, 2001. 163p. Dissertação (Mestrado em Zootecnia) - Universidade Federal de Viçosa, 2001.

SNEDECOR, G.W.; COCHRAN, W.G. Statistical methods. 8.ed. Iowa: Iowa University Press, 1989. 503p.

Van SOEST, P.J.; ROBERTSON, J.B.; LEWIS, B.A. Methods for dietary fiber, and nonstarch polysaccharides in relation to animal nutrition. Journal of Dairy Science, v.74, n.10, p.3583-3597, 1991.

ZERVOUDAKIS, J.T.; PAULINO, M.F.; DETMANN, E. et al. Desempenho e características de carcaça de novilhos suplementados no período das águas. Revista Brasileira de Zootecnia, v.30, n.4, p.1381-1389, 2001.

Recebido em: 29/06/02 Aceito em: 06/05/03 